\title{
Digital sketch maps in teaching GIS for law enforcement students
}

\author{
Andrea Pődör ${ }^{\mathrm{a} *}$, László Zentai ${ }^{\mathrm{b}}$, Erika Gál ${ }^{\mathrm{c}}$ \\ ${ }^{a}$ Institute of Geoinformatics, University of Óbuda, Alba Regia Technical Faculty, Székesfehérvár, Hungary; \\ podor.andrea@amk.uni-obuda.hu \\ ${ }^{b}$ ELTE Eötvös Loránd University, Department of Cartography and Geoinformatics, Budapest, Hungary; \\ lzentai@caesar.elte.hu \\ ${ }^{c}$ National University of Public Service, Faculty of Law Enforcement, Department of Public Order and Traffic Policing, Budapest, \\ Hungary; gal.erika@uni-nke.hu \\ * Corresponding author
}

\begin{abstract}
This paper presents a project-based learning method designed by teachers of GIS for students in public order. The aim of the method is to utilize GIS technologies for analysing digital sketch maps made after interviewing people by students. This method gives a hands-on experience of the students about the subjective feelings of the citizens of the examined settlements. For the projects, a paper-based survey and a web application in the form of digital sketch maps were used.

The article shows the process of projects used in the studies of public order. The methods applied in the phase of planning, processing and visualising of the data are explained in the case of digital sketch maps and of paper-based surveys. Some general findings of the project are also introduced as well as the students' opinion of the effectiveness of the projects.

General findings show that the results of the students correlate with observations found in the literature. It is evident that more informatics the students acquire during their everyday routine, the more useful and beneficial they find the usage of Geographical Information Systems and the project of using digital sketch maps of fear of crime in different cities.
\end{abstract}

Keywords: fear of crime, project-based learning, GIS in public order

\section{Introduction}

Crime mapping nowadays is an integral part of policy work for law enforcement bodies. As the definition says, "crime mapping is the process of using a geographic information system [GIS] to conduct spatial analysis of crime problems and other police-related issues." (Boba, 2005).

Two master courses are offered for the students who wish to continue their studies at the Faculty of Law Enforcement of the National University of Public Service in Hungary. One is deepening the knowledge of those who are interested in forensics sciences, the other is proposed for students who will be leaders in law enforcement.

In the latter MA, students may acquire differentiated professional skills for 21-26 credits, such as theoretical knowledge, public-order skills, assessment-analytical skills, professional knowledge of organized crime.

Within this subject group, the academics designing the two-year MA programmes on law-enforcement leader strived to incorporate up-to-date knowledge into the curriculum and to insert GIS as a mandatory course from the differentiated skills into the public order professional skills.

The course has been taught since 2014, and the teachers are continuously developing the content of the course.
At the beginning, it became clear that students involved in the course were not skilled enough in information technology and spatial sciences. Therefore, it seemed to be a good idea to use a kind of extracurricular practical work to bring closer GIS technologies.

As a project-based learning process, it was successfully implemented in other courses of GIS (Pődör, 2011, Pödör\&Zentai, 2017). The authors thought that it would be beneficial to utilize this type of teaching method for students in public order as well.

\section{GIS subject in the Public Order Specialisation}

The aim of the subject is to familiarize students with the basic operations of GIS and their applicability in law enforcement practice. During the semester, students acquire knowledge of Spatial Data Management: Spatial Databases. They learn about some GIS systems currently operating abroad and at home. The main competencies acquired by students during the semester are as follows: understanding the application of GIS in police practice and law enforcement operations, the application of GIS in decision-making and measuring effectiveness.

The students who choose this subject have a practical background in the field of public order. Many of them design public order activities as a daily routine, such as planning blocking, cordoning the places for checkpoints 
and roadblocks, high and low-profile crowd management, and security management.

It is still typical that they are not using the potentials of GIS software: it is common that if they need to draw a map they just use the Google map combined with a simple drawing program like Paint or Photoshop or the Robotzsaru Neo map developed by the Hungarian police.

Therefore, the teachers primarily wanted to introduce them the basic operations of GIS in order to help them in their everyday routine. It was also an aim to show them the spatial preferences of city dwellers from the point of view of crime so that they consider this information in planning the patrol service. For this requirement, the theory and practice of fear of crime was also introduced.

As shown in the literature, the fear of crime is strongly related to prejudice (Skogan, 1995), and preconceptions have an essential role in judging the crime situation. According to numerous studies, prejudice is present in Hungarian society too (Váradi, 2014); consequently, it influences the opinion of citizens (Pödör \& Dobos, 2014; Pődör \&Jakobi, 2018).

\section{Method}

Projects were used as an extracurricular activity during the semester. The projects exploited the results of mental mapping of a given area conducted by the students.

\subsection{Digital sketch maps used in the projects}

Mental and digital sketch maps have been utilized in numerous investigations (Boschmann and Cubbon, 2014) to translate subjective experience of citizens such as fear, emotions, or stress. Mental maps are devices for social geography to comprehend human practices dependent on citizens groups' impression of their spatial condition, while digital sketch maps have been utilized in participatory and subjective geographic data frameworks to portray spatial narratives of groups of people (Boschmann and Cubbon, 2014).

Mapping the fear of crime and emotional mapping share many similarities, as fear is fundamentally identified with feelings. A few research papers are dealing with emotional mapping (e.g., Panek et al. 2016), in which web applications gather the emotional view of urban space. A more perplexing study (Resch et al., 2015) utilizes specialized and human sensors and georeferenced online life posts, from which the analysts separate emotional data. For the present study, a website on data acquisition application was used designed by one of the authors. The application was tested several times in advance (Pödör et al. 2016; Pődör\&Jakobi, 2018).

The webpage itself utilises the Google native web API, and the drawing function is available through Drawing Manager. The webpage is available at http://bunmegelozes.amk.uni-obuda.hu (Fig. 1). The respondents can use the webpage without registration. There is a short questionnaire where they should indicate their postcode, age, gender and usual mode of transport, as according to the literature these facts influence the perception of fear of crime as well (Doran \& Burgess,
2012). After finishing the responses to these questions, the user finds a short user guide of how to create digital sketch map. Following the instructions, they can draw polygons around the places where they feel safe; with another tool, they can indicate those places where they feel fear of crime.

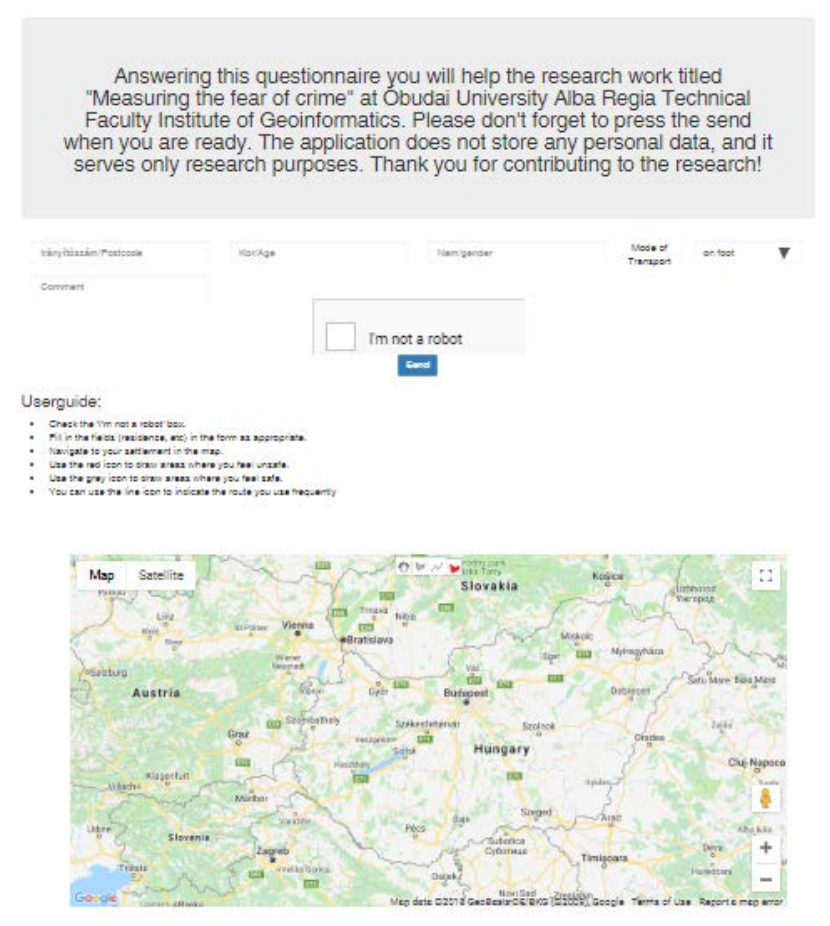

Figure 1 . The webpage used by the participants.

\subsection{Surveys applied in the projects}

Especially at the beginning of the new course in 2014, some of the students (mainly those who had no confidence in using informatics as an everyday routine) felt some aversion towards using the webpage. For them, the teacher offered the usage of a paper-based questionnaire supplemented with a map designed by Pödör \& Dobos in 2014. The survey contained thirteen questions. Five of the questions asked for personal information: age, sex, marital status, number of children, and type of the place of residence. Eight questions referred to the status of the public safety, the habitat of the offenders, whether the respondent had ever been a victim of crime, and their opinion about law enforcement strategies in the given settlement. The last two questions were related to a map included in each questionnaire. The map of the analysed settlement showed the zones defined in the integrated urban development strategy of the settlement. In the penultimate question, the respondents had to categorize each zone to their relative safety. They had four choices: (1) safe, (2) less safe, (3) dangerous, and (4) avoid during night. It was also possible to combine categories: safe but to be avoided during night. The last question required significantly more time from the participants as they had to categorize each zone according to the most typical crime types. Using different crime types, they had to create a ranking of zones. The crime types were as follows: violent crimes against persons, theft, car and motor theft, car breaking, burglary, vandalism, robbery, violence and 
disruption and offence against property. These crime types are shown also on the official crime map of the Hungarian police (http://www.police.hu/bunugyiterkep). The first zone in the rank meant that the respondent thought that a given type of crime was most typical in that zone, and the last meant the least typical (Pödör \& Dobos, 2014).

As more and more students arrived with higher level of IT knowledge, they preferred to choose the web application in their project.

\subsection{Project planning, data collection and processing the digital sketch maps}

The project tasks in each year consists of the following parts: (1) Project planning, (2) data processing and (3) analyses. The project planning starts with the discussion with the students. The teachers explain to them some theories such as fear of crime and mental mapping. Some of the successful projects prepared in the previous year are also introduced to them. As the time for this course is usually limited to 10 contact hours only, the authors think that the project-based learning should be more effective for the students; this is why the contact hours are used to process the data so that they can meet the processing capability of GIS software. The main goal of the whole project is to raise the interest of the students in spatial analyses and tools.

Digital sketch maps as a data acquisition method are used in this process. The students should contact local people and ask them to participate in the survey.

When the sufficient number of responses is available, the data are processed together with the students using some basic GIS operation as described later.

When the processed maps are ready, the students should analyse the maps and should write a minimum 10-page essay about the result.

The first part of the project for the students starts with the decision which settlement they should involve in their study. A key point of the success of the project is collecting a sufficient number of responses. The participants agreed that the ideal number would be 100 . However, experience showed that the people were reluctant to participate in such surveys and it was very difficult to gather so many answers. Therefore, it was decided that responses more than fifty should also be processed, because this number was considered enough to see the initial preferences of citizens.

Another key point was that the students should know the settlements fairly well to understand the results of the surveys and digital sketch maps.

The next step of the project was the processing of the data. The web page used the MySQL DataBase Management System, and phpMyAdmin provided an interface for connection to the students' database. The original data were processed by the teachers in order to get the polygons drawn by the respondents in the form of ESRI shape files. All the polygons created by the respondents during a given period resulted in one shape file (Fig. 2.), and then the teacher sorted the polygons by the settlements.
The students worked with these polygons connected to their area of interest by using basic GIS operations. First, they had to separate polygons indicating safe places from polygons marking fearful places. Here they got two separate shape files. Then, all types of polygons were covered by a $200 \times 200 \mathrm{~m}$ grid. The students aggregated the number of overlapping polygons using the grid to be able to perform basic GIS calculations to evaluate the results. As also other social data are available in such grid forms in Hungary, it seemed to be reasonable to choose the same grid system for later analyses (Pödör\&Jakobi, 2018).

Those who used the paper-based survey usually only analysed the responses with the help of a spreadsheet program with which they created graphs and tables about the results. Some of the students also visualised the results on a map as well.

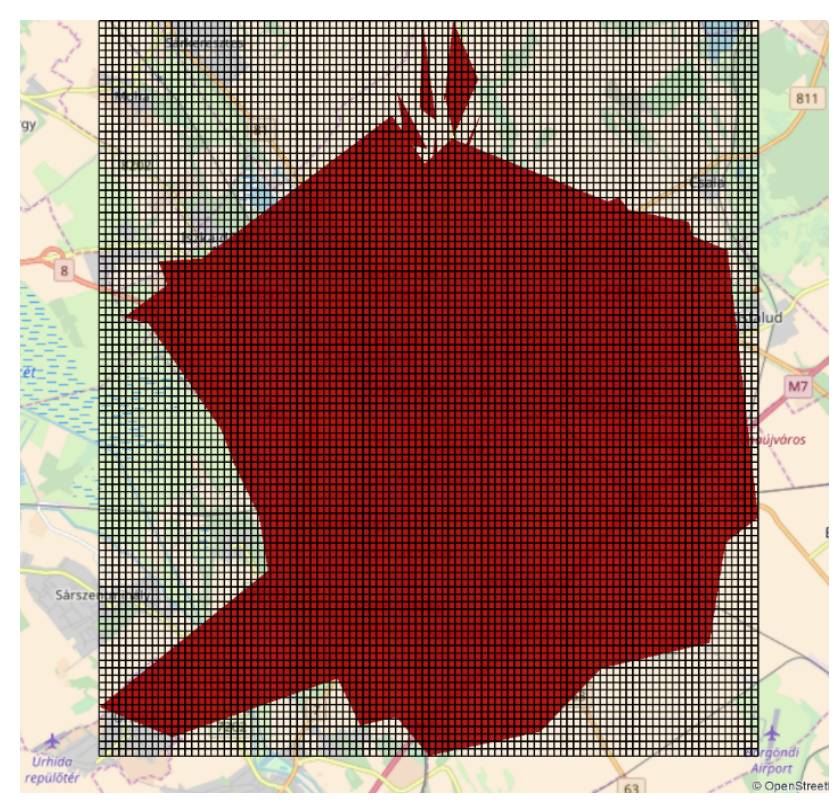

Figure 2. The processing of the data.

\subsection{Visualisation and analyses}

After pre-processing the data, simple visualisation tools were used to draw the maps.

A straightforward method, the use of green and red colours was applied on the maps. The teachers used the preprocessed data for experiments with the students to understand the importance of having adequate knowledge of the different built-in classification methods of the GIS software, since students had only limited cartographic knowledge.

The pre-processed data were visualised with different classification methods. Each data classification technique created distinctive choropleth maps. Nevertheless, using a different method can offer a different explanation about the map. The students should realize that with using the same data in each choropleth map, they could obtain various results, and without understanding the classification methods, they cannot give real explanations. It is very important to know the differences between these methods, unless they use the inappropriate method and 
produce a misleading result with the thematic maps. The teachers explain to the students that understanding the differences between the classification methods and the usage of the histogram can help them. The $\mathrm{x}$-axis of histograms shows the range of values in the fields, the yaxis is a count of features. The vertical blue lines in the histogram are class-breaks. The grey column refers to the percentage of the value range. The default number of grey columns is one hundred, which can be modified from 10 to 100 . No grey column in a value range means that no feature falls within it. For example, QGIS has six classification methods. The project analysed the impact of the different classification methods with the help of collected data.

Finally, the project group agreed in which method to use; this was mostly the natural breaks method, because they felt that using this method makes the maps visually more appropriate for the viewer.

The students created two maps: one for safe places where the grids were coloured by the shades of green, and another map for places of fear where the grids were coloured by the shades of red. Naturally, where the hue was darker, more marks indicated the given area. Similarly, where lighter hue was used for colouring, the grid had a lower value. The labelling of the numbers of overlapping polygons within a grid can also be added.

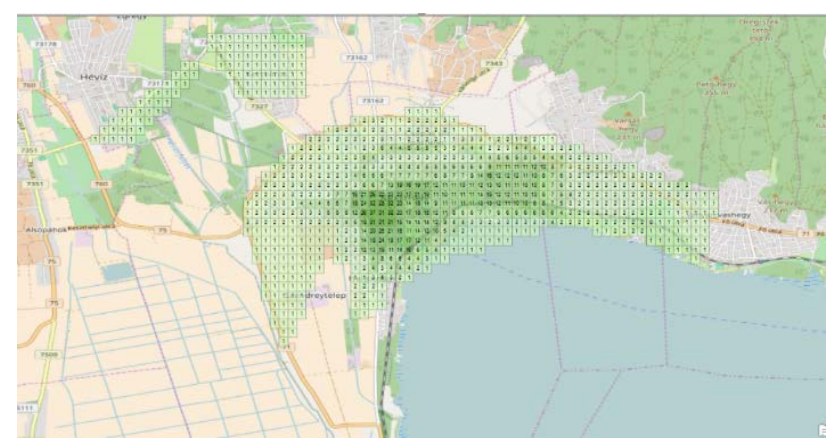

Figure 3. Grids indicating safe places in the city of Keszthely.

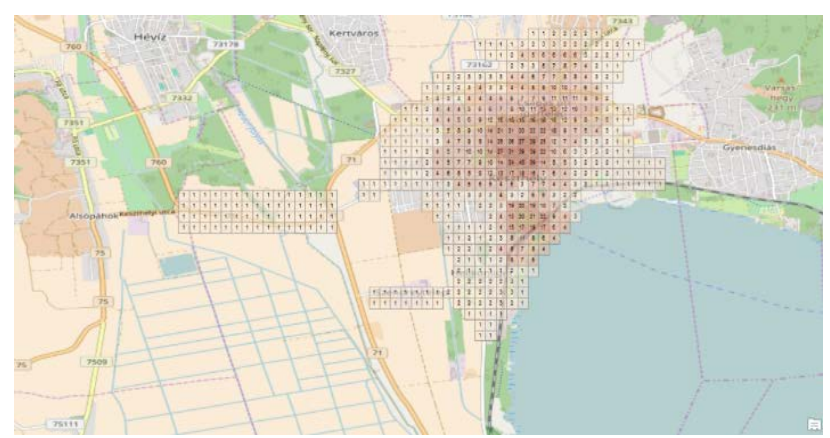

Figure 4. Grids indicating unsafe places in the city of Keszthely.

The students can use these two maps for further analyses. Some of the students who used paper-based survey can visualise some of the results on different types of maps.

As mentioned, some of the students used a paper-based survey instead of digital sketch maps. In the questionnaire, the last two questions are related to a map. In each questionnaire, the students should include the different zones of the given settlement and map could help the respondents identify the places.

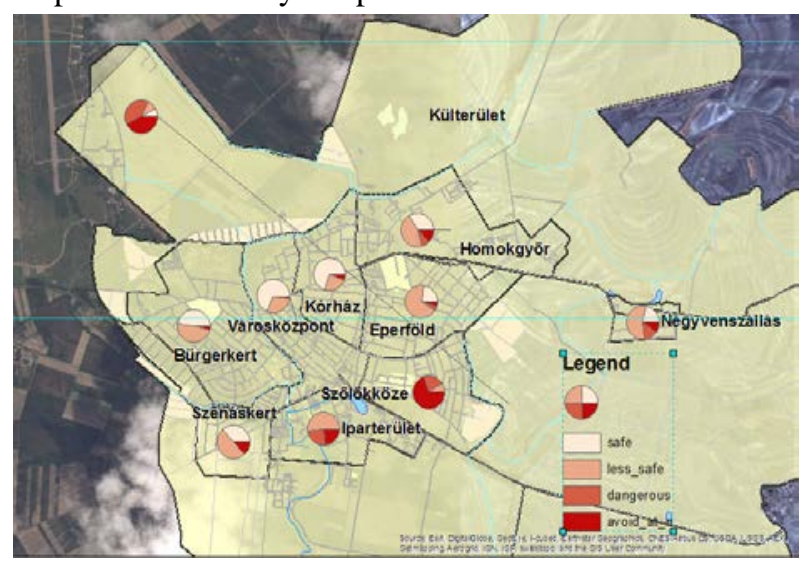

Figure 5. Visualising the relative safety of different zones in the case of Kalocsa.

In one question, they had to evaluate the status of the public safety of the previous year of each zone. For the visualisation of these data, a simple diagram method with the option of pie charts was used, as this method can show exactly the proportions (Fig. 5). The respondents had to categorize each zone to their relative safety. The diagram can show in what proportion of the four options were chosen. The four choices were (1) safe, (2) less safe, (3) dangerous, and (4) avoid during night (Pődör \& Dobos, 2014).

For depicting the answers to the last question, the diagram method was used, although bar charts were added to show exactly the ranking of the different zones according to subjective rank in the given crime types. Here the respondents had to create a ranking of all the zones of the investigated settlement. The first zone in the rank meant that the respondent thought that a given type of crime (see 3.2) was most typical in that zone, the last meant the least typical. Sometimes the diagram was combined with the actual number of crimes per inhabitant with a choropleth map using the natural breaks classification.

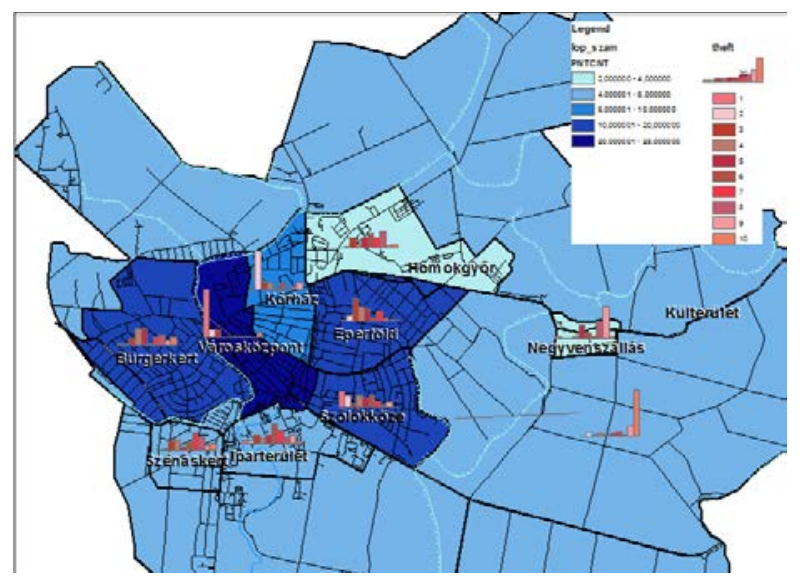

Figure 6. Ranking of the zones according to fearful places by red diagrams, compared to the number of crimes in the case of thefts in Kalocsa.

For these projects, the teachers prepared the spreadsheetprocessed data for visualisation. 


\subsection{Survey on the usability of the GIS in public order studies}

In order to assess the students' opinion on the usefulness of the subject, the teachers created a questionnaire with twelve questions. Most of the questions were multiplechoice types. The first section of the questionnaires incorporated information about the year of the study and the general IT knowledge of the students. In the second section, they had to indicate that during the practice how well they could acquire basic GIS operations, spatial database management, how hard it was to fulfil the requirements of the project task. In the next section, they indicated the usefulness of GIS in law enforcement, public order practice and in decision support. In addition, they were asked whether they knew any GIS application in law enforcement practice used abroad or in Hungary. The last section inquired about future development areas that could be involved in the education. The students had the opportunity to comment or give recommendation concerning the subject GIS in public order studies.

\section{Results}

Since 2014, the teachers have been involving students in these projects, which investigated several cities, so now they can have a general overview of the cities. At the same time, it is important to examine the efficiency of these projects.

\subsection{Results of the projects}

The students investigated altogether 26 cities, 2 counties and some of the districts of Budapest. The following cities and settlements were involved in the studies (see the number of inhabitants in brackets).

- 2014: Bugac (3006), Eger (53,436), Kalocsa $(16,136)$, Kenderes (4508), Keszthely $(19,652)$ Hajdú-Bihar County, Bács-Kiskun County traffic accidents.

- 2015: Debrecen (202,214), Budapest districts V, XIII, and XXII.

- 2016: Bük (3544), Eger $(53,436)$, Győrújfalu (1211), Jászberény (26,622), Mátraterenye (1873), Nyírbátor $(12,259)$, Szekszárd $(32,156)$, Szigethalom (13,745), Újfehértó (13,611), Zalaegerszeg $(61,970)$.

- 2017: Tapolca $(16,035)$, Debrecen, Jászberény, Siófok $(25,468)$, Budapest all districts as zones.

- 2018: Balmazújváros (17,109), Budapest districts $X$ and XXIII, Heves $(10,275)$, Miskolc $(157,639)$, Nyíregyháza $(117,874)$, Ózd (32,827), Veszprém $(56,927)$.

It is evident of the list that large, medium and small settlements were equally examined. Considering the geographical distribution of the settlements, all the different regions of Hungary have been represented in the investigation. In terms of the number of paper-based surveys and the application of web page, it is observable that at the beginning in 2014 all the students used paperbased surveys. In 2016 all the students, in 2017 except one used the web page for data acquisition. In 2018, 10 out of 14 used the webpage, others used the digital form of the original paper-based survey.

As the structure of the cities are different, examining all the results showed that people's subjective view of safe places usually defined the inner cities and peaceful residential areas.

Correspondingly, the places where people possibly feel fear of crime are in correlation with places where a higher concentration of socially disadvantaged population is observable, also where municipal social housing or homeless shelters are in the area, where public lighting is poor, or where there is a larger share of ethnic minorities. These findings are in consensus with the observation found in the literature (Pődör \& Dobos, 2014; Pődör \&Jakobi, 2018). It is also characteristic that in comparison with the official crime statistics the above-mentioned places significantly differ in terms of criminal infiltration. The inner cities are more affected with crime than other areas, and places connected to socially disadvantaged people does not show higher percentage of crime as other areas of the settlements.

It is typical that a significant overlap can be observed in the case of traffic and commercial centres. Citizens regularly indicate fear where the train and bus stations and the main shopping mall can be found, and official crime statistics demonstrates the same phenomenon.

\subsection{Results of the surveys of the students}

Since 2014, approximately 40 students were involved in the project. From them, 19 responded to the questionnaire. $42 \%$ of the respondents attended the course in 2018, $26 \%$ in 2014, $10 \%$ in 2016, and 21\% in 2017. No one participated in the year 2015. The majority of the respondents (73\%) have basic IT knowledge, $23 \%$ of them have an ECDL exam.

As for the GIS knowledge acquired during the course, the majority of the students (approximately 70\%) indicated their knowledge on the scale of 1-5, where 5 meant the best score and 1 was the worst. On average, they could learn basic GIS operation on a medium level. Only two of them indicated that they could learn everything. The survey got almost the same result in the case of database management and analyses. Although one student indicted that it was not possible to achieve the learning skills in this field.

According to the level of difficulty of the project task, 2 students found it an easy task, two of them indicated as extremely difficult, the majority of them (40\%) marked as moderately and $21 \%$ of them not so difficult.

Concerning the applicability of the gained skills, the majority of the students (70\%) think that with appropriate IT knowledge it is employable in law enforcement practice, the others think that it can be employable partially.

As regards the applicability in public order practice, the answers were not so positive, as $10 \%$ percent of the students think that this knowledge cannot be applied, although 53\% think that it is fully applicable, the other $37 \%$ think that it is partially employable. 
With respect to the question as how well GIS tools support law enforcement decisions in Hungary, the opinions were quite divided. Two of the students think that the tools fully support, one of them thinks that they do not support the decisions at all, the majority of the students (42\%) thinks that they are supporting in a moderate level, 26\% think that mostly supports.

Only two of them know GIS decision support systems used in Hungary or abroad, the others do not have any information about this. In their answer, the application used by the Hungarian police corps (TIR NOVA) was mentioned.

The students were also asked to rank on a 1-5 scale some future topics that can improve the training in the future of the course. The topics were national and international legal issues, IT knowledge, national and international law enforcement databases and special GIS software designed for law enforcement corps. They could mark with 1 the area that is least important and with 5 the area of development that is most important.

The results show that students would like to learn more about GIS software and they would like to gain more IT knowledge as well. For the majority of them the legislation background is the least important issue.

The students highlighted the need of the access to the application of up-to-date law enforcement databases.

Generally, the result seems to be promising as the students having a background without any GIS, Geography and Cartography knowledge could acquire basic GIS analysis and data management skills.

\section{Conclusions}

The findings support the idea that implementing digital sketch maps of fear of crime created through a website in the GIS course has several advantages. The projects revealed that during one semester it was possible to reach concrete results detecting the unsafe and safe areas in the investigated settlements. In addition, the students could be involved in the data acquisition, data processing and analysing phase of the projects.

The experience showed that in line with the level of IT knowledge the students increasingly used the webpage application rather than the paper-based survey.

This project-based approach is also very helpful to understand the whole process of map-making, but especially to practice and understand the pitfalls of the cartographic visualization methods implemented in GIS software.

In these project-based learning processes, the students have to invest extra-curricular work investigating their own study area.

Concerning the survey results of the students, they are convinced of the importance and applicability of GIS.

\section{References}

Boba, R. (2005). Crime Analysis and Crime Mapping. Thousand Oaks, CA: Sage Publications

Doran D. J. \& Burgess M. B. (2012). Putting Fear of Crime on the Map: Investigating Perceptions of Crime Using Geographic Information Systems. New York, NY: Springer.

Pánek, J., Pászto, V. \& Marek, L. (2017). Mapping emotions: spatial distribution of safety perception in the city of Olomouc. In: GIS Ostrava 2016 - The Rise of Big Spatial Data. Springer Lecture Notes in Geoinformation and Cartography, 211-224.

Pődör A. (2011). The Methodological Advantages of Using Web Server in Teaching GIS, In: Anne Ruas (ed.) Advances in Cartography and GIScience. Volume 2: Selection from ICC 2011, Paris., 2011.07.03-2011.07.08. Berlin; Heidelberg: Springer Science+Business Media, 2011. pp. 73-82. (Lecture Notes in Geoinformation and Cartography; 6.)

Pődör A. \& Dobos, M. (2014). Official crime statistics versus fear of crime of the citizens in a Hungarian small town. In: R. Vogler, A. Car, J. Strobl \& G. Griesebner (Eds.), GI_Forum 2014 - Geospatial Innovation for Society. Berlin: Herbert Wichmann. pp. 272-275

Pődör A. \& Jakobi Á. (2018). Digital Sketch Maps Detecting Places of Fear of Crime. In: Igor, Ivan; Jan, Caha; Jaroslav, Burian (eds.) GIS Ostrava 2018 - GIS for Safety \& Security Technical University of Ostrava, pp. 22-32.

Pődör, A., Révész, A., Rácskai, P., \& Sasvár, Z. (2016). Measuring citizens fear of crime of using a web application - A case study. GI_Forum, 2, 123-133. doi: 10.1553/giscience2016_02_s123

Pődör, A. and Zentai, L., (2017). Educational Aspects of Crowdsourced Noise Mapping. In International Cartographic Conference pp. 35-46. Springer, Cham.

Resch, B., Summa, A., Sagl, G., Zeile, P. \& Exner, J.-P. (2015). Urban emotions - geo-semantic emotion extraction from technical sensors, human sensors and crowdsourced data. In: G. Gartner \& H. Haosheng (Eds.), Progress in Location-Based Services 2014, Cham, Switzerland: Springer. pp. 199-212.

Skogan, W. G. (1995). Crime and the racial fears of white Americans. The Annals of the American Academy of Political and Social Science, 539(1) 59-71.

Váradi, L. (2014). Youths Trapped in Prejudice, Politische Psychologie. Wiesbaden: Springer Fachmedien 